\title{
The decline of typhoid and the rise of non-typhoid salmonellae and fungal infections in a changing HIV landscape: bloodstream infection trends over 15 years in southern Vietnam
}

\author{
Tran Vu Thieu Nga ${ }^{a}$, Christopher M. Parry ${ }^{a, b}$, Thuy Le ${ }^{a, c}$, Nguyen Phu Huong Lan $^{\mathrm{d}}$, \\ To Song Diep ${ }^{\mathrm{d}}$, James I. Campbell ${ }^{\mathrm{a}, \mathrm{e}}$, Nguyen Van Minh Hoang ${ }^{\mathrm{a}}$, Le Thi Dung ${ }^{\mathrm{d}}$, John Wain ${ }^{\mathrm{f}}$, \\ Christiane Dolecek ${ }^{\mathrm{a}, \mathrm{e}}$, Jeremy J. Farrar ${ }^{\mathrm{a}, \mathrm{e}}$, Nguyen Van Vinh Chau ${ }^{\mathrm{d}}$, Tran Tinh Hien ${ }^{\mathrm{a}, \mathrm{e}}$, \\ Jeremy N. Day ${ }^{\mathrm{a}, \mathrm{e}}$, Stephen Baker ${ }^{\mathrm{a}, \mathrm{e}, *}$ \\ a The Hospital for Tropical Diseases, Wellcome Trust Major Overseas Programme, Oxford University Clinical Research Unit, 190 Ben Ham Tu, Quan 5, Ho Chi \\ Minh City, Vietnam \\ ${ }^{\mathrm{b}}$ Angkor Hospital for Children, Wellcome Trust Major Overseas Programme, Mahidol University-Oxford University, Clinical Research Unit, Siem Reap, \\ Cambodia \\ c Hawaii Center for AIDS, University of Hawaii at Manoa, Honolulu, USA \\ d The Hospital for Tropical Diseases, Ho Chi Minh City, Vietnam \\ e Centre for Tropical Diseases, University of Oxford, Oxford, United Kingdom \\ f Laboratory for Gastrointestinal Pathogens, HPA Centre for Infections, Colindale, United Kingdom
}

\section{A R T I C L E I N F O}

\section{Article history:}

Received 21 June 2011

Received in revised form 4 October 2011

Accepted 4 October 2011

\section{Key words:}

Vietnam

Bloodstream infections

Salmonella Typhi

Antimicrobial resistance

HIV infection

\begin{abstract}
A B S T R A C T
The etiological spectrum of bloodstream infections is variable between industrialized and developing countries and even within a defined location over time. We investigated trends in bloodstream infections at an infectious disease hospital in Ho Chi Minh City, Vietnam, from 1994-2008. Amongst 66111 blood cultures performed, a clinically relevant pathogen was isolated in 7645 episodes (positivity rate; $116 / 1000$ cultures). Salmonella Typhi was the predominant pathogen until 2002; however, a considerable annual decline in the proportion of $S$. Typhi was observed (OR 0.6993, 95\% CI [0.6885, 0.7103], p < 0.0001). Conversely, there was a significant increase in the proportions of non-typhoidal Salmonella (NTS), Cryptococcus neoformans and Penicillium marneffei, concurrent with increasing HIV prevalence. These data document a substantial longitudinal shift in bloodstream infection etiology in southern Vietnam. We propose such changes are related to increasing economic prosperity and HIV prevalence, and this pattern marks a substantial change in the epidemiology of invasive salmonellosis in Southeast Asia.
\end{abstract}

(C) 2011 Royal Society of Tropical Medicine and Hygiene. Published by Elsevier Ltd. All rights reserved.

\section{Introduction}

Bacteriological and mycological investigations of bloodstream infections demonstrate extensive geographical

\footnotetext{
* Corresponding author. Tel.: +84 89241761; fax: +84 89238904

E-mail address: sbaker@oucru.org (S. Baker).
}

diversity in etiology and the proportions of isolated bacteria that exhibit resistance to antimicrobials. ${ }^{1,2}$ An understanding of the epidemiology of bloodstream infections in different locations is crucial in the development of rational management and treatment guidelines. In many developing countries in Asia, Salmonella Typhi is the predominant organism isolated from the blood of febrile patients, and isolates that are multidrug resistant (MDR) or exhibit decreased susceptibility to fluoroquinolones 
have become dominant. ${ }^{3,4}$ In addition, $S$. Paratyphi A is recognized as an increasingly important agent of bloodstream infections in Asia, accounting for up to $50 \%$ of all Salmonella bloodstream isolates among febrile patients in some locations. ${ }^{5,6}$

Bloodstream infections in some developing countries in sub-Saharan Africa are characterized by a high proportion of salmonellae that are, in developed countries, associated with gastroenteritis rather than invasive disease. ${ }^{7,8}$ This emergence of invasive non-typhoidal Salmonella (NTS) infections has been coupled with the African HIV epidemic. ${ }^{9,10}$ As such, these NTS infections appear to be aggressive, characterized by a high mortality and recurrence rate, compounded by the emergence and increasing proportion of circulating MDR strains ${ }^{11,12}$ Additional pathogens, such as Streptococcus pneumoniae, Cryptococcus neoformans, Penicillium marneffei and Mycobacterium tuberculosis, are also related to HIV infection, and are becoming common, exhibiting varying epidemiological patterns in Africa and Asia. ${ }^{13,14}$ Furthermore, as with MDR Salmonella, increasing resistance to antimicrobial agents in important pathogens, such as the increase in penicillin resistance in invasive Streptococcus pneumoniae in several Asian countries, the emergence of third generation cephalosporin resistance in Gram negative bacteria and the intercontinental spread of MRSA, have a major public health significance for disease treatment and control. ${ }^{15,16}$

The majority of studies of bloodstream infections are conducted over short time periods, ${ }^{17,18}$ therefore, limited longitudinal cross-sectional data regarding infecting agents and their antimicrobial susceptibilities prevents the elucidation of significant trends over longer time periods. The inevitable population shift from rural to urban life in Vietnam and the corresponding changes in the underlying risk factors for infectious diseases are posing new clinical and public health challenges. Here, we have retrospectively studied bloodstream infections and their antimicrobial resistance patterns in admitted patients at the major infectious disease hospital in southern Vietnam over a 15-year period.

\section{Material and methods}

\subsection{Study site}

This study was performed retrospectively with routine anonymous laboratory data; individual patient consent was not required. The hospital for tropical diseases (HTD) is a 550-bed hospital that serves as a main primary and secondary facility for the surrounding local population in Ho Chi Minh City (HCMC) and a tertiary referral center for infectious diseases for the 17 southern provinces of the country, with a catchment population of approximately 40 million people. Nearly $70 \%$ of HTD admissions are resident in HCMC, with the remainder resident in the surrounding provinces. Neonates, patients without infectious diseases, including those with surgical requirements, tuberculosis, cancer, primary hematological disorders or immunosuppression (other than HIV) are referred to other hospitals within HCMC.

\subsection{Study population}

Systematic criteria concerning which patients should have blood cultures performed were not used during the course of the study. In general, a blood culture was performed by the admitting team in patients in whom an infection was suspected on the basis of a fever $\left(>38^{\circ} \mathrm{C}\right)$ or who had evidence of sepsis on the basis of the presence of two or more of the following features: fever $\left(>38^{\circ} \mathrm{C}\right)$ or sub-normal temperature $\left(<36^{\circ} \mathrm{C}\right)$; tachycardia (exact level according to age); tachypnea (exact level according to age); an elevated white cell count ( $>12000$ cells $/ \mathrm{mm} 3$ ) or depressed white cell count $(<4000$ cells $/ \mathrm{mm} 3)$. We have no reason to believe there was a systematic change in the application of these criteria during the time course of the study. Therefore, all patients with or without HIV admitted to the hospital who had a blood culture performed for suspected bloodstream infection between 1 January 1993 and 31 December 2008 were included in this retrospective study. Routinely, a member of the hospital staff recorded the date of blood draw, the patient's age, sex, and suspected diagnosis, the number of blood culture bottles inoculated, the result of the culture (whether positive or negative) and the susceptibility of the isolate to commonly used antimicrobial agents. These are the source data for this study. Data from records was subsequently entered into Excel (Microsoft office v12, Microsoft Corp, Redmond, WA, USA). The number of patients admitted to the hospital annually was obtained from hospital records.

\subsection{Microbiological blood culture and antimicrobial susceptibility testing}

For blood cultures taken between 1993 and September 1997 a manual blood culturing system was used. ${ }^{4}$ In September 1997, a BACTEC culture system (Becton Dickinson, Franklin Lakes, NJ, USA) was introduced. After a period of overlap between September 1997 and March 1998 when both systems were used, the BACTEC system was used alone. For blood culturing, $8-15 \mathrm{~mL}$ of venous blood from adults and $2-5 \mathrm{~mL}$ of venous blood from infants and children was obtained. For the manual blood culture system, $5 \mathrm{~mL}$ aliquots of blood were inoculated into separate bottles containing $50 \mathrm{~mL}$ of brain-heart infusion broth (Oxoid, Basinstoke, UK) with $0.05 \%$ sodium polyethanolsulphonate (Sigma-Aldrich Corp., St Louis, MO, USA). Blood cultures were vented and incubated at $37^{\circ} \mathrm{C}$ and 'blind' subcultures were performed at 24 and 48 hours and 7 days post inoculation or whenever there was visible growth in the culture bottle. For the BACTEC blood culture system, $5-8 \mathrm{~mL}$ aliquots (for adults) or $2-5 \mathrm{~mL}$ aliquots (for infants and children) of venous blood were inoculated into BACTEC plus aerobic bottles (Becton Dickinson). Inoculated BACTEC bottles were incubated at $37^{\circ} \mathrm{C}$ in a BACTEC 9050 automated analyzer for up to five days and sub-cultured when the machine indicated a positive signal. Patients with Mycobacterium tuberculosis and other mycobacterium species were not included in the study since mycobacterial blood culture is not routinely performed at the hospital.

All sub-cultures were performed onto fresh sheep blood agar, on chocolate agar if Haemophilus influenzae or 
Neisseria meningitidis was suspected, or onto Sabouraud's agar if a yeast or mold was suspected (all media was supplied by Oxoid Unipath, Basingstoke, UK). Plates were incubated at $37^{\circ} \mathrm{C}$ in air (for blood-agar), $5 \% \mathrm{CO}_{2}$ (for chocolate agar) for 48 hours, or $30^{\circ} \mathrm{C}$ in air (Sabouraud's agar) for 5 days. Organisms were identified by standard methods including API20E identification kits (Bio-Mérieux, Craponne, France) where possible. Specific antisera were used to identify the serogroup of Salmonella isolated, including Vi to identify $S$. Typhi.

The susceptibility to relevant antimicrobial agents was determined by the modified Bauer-Kirby disc diffusion method. Enterobacteriaceae were tested with discs containing chloramphenicol $(30 \mu \mathrm{g})$, ampicillin $(10 \mu \mathrm{g})$, co-trimoxazole (trimethoprim $1.25 \mu \mathrm{g} /$ sulfamethoxazole $23.75 \mu \mathrm{g})$, ceftriaxone $(30 \mu \mathrm{g})$, ofloxacin $(5 \mu \mathrm{g})$ and gentamicin $(10 \mu \mathrm{g})$. Salmonella Typhi and S. Paratyphi A were not tested with gentamicin, but were tested with nalidixic acid $(30 \mu \mathrm{g})$. Methicillin susceptibility of Staphylococcus aureus was tested using $25 \mu \mathrm{g}$ methicillin strips on Mueller Hinton agar incubated at $30^{\circ} \mathrm{C}$. The susceptibility of Streptococcus pneumoniae to penicillin was tested with a $1 \mu \mathrm{g}$ oxacillin disc. The zone sizes were recorded in the laboratory record book. The breakpoint zone size interpretations were adjusted according to the CLSI guidelines of 2010 to provide consistency throughout the time period. ${ }^{19}$

\subsection{HIV status and testing}

Patients who were known to be HIV-infected, i.e. those who were referred for admission from the HIV clinic, received an International Classification of Diseases (ICD-10) code B20 at the hospital. HIV infection was confirmed using one the following approved antibody assays, Determine HIV1/2, AxSYM HIV1/2 gO, Genscreen HIV V.2, Serodia HIV1/2, or Murex Ag/Ab Combo according to Vietnamese and World Health Organization (WHO) guidelines. ${ }^{20,21}$ For patients admitted with unknown HIV status, HIV testing was generally performed at the discretion of a clinician for suspected cases and not for screening purposes. The ICD code B20 was routinely recorded in all laboratory request forms and in the record book.

\subsection{Definition of a bloodstream infection episode}

A bloodstream infection episode in this study was defined as isolation of at least one clinically relevant pathogen from one blood culture, drawn from a patient with a clinical syndrome indicative of a bloodstream infection. Episodes were identified from the electronic database as detailed above. As it was not practical to obtain and review the hospital records of all patients with a positive blood culture episode to ascertain whether a pathogen was clinically relevant for that particular patient, the following potential contaminant organisms were excluded: coryneforms (Corynebacterium, etc.), coagulasenegative staphylococci, micrococci, Propionibacterium, Bacillus, alpha hemolytic streptococci, environmental Gram-negative bacilli, non-pathogenic Neisseria and nonpathogenic Penicillium. The overall contamination rate of these organisms was not estimated here, but we have previously estimated the contamination rate at this location to be $2.4 \% .{ }^{4}$ Additionally, we could not retrospectively determine whether the infection episode was community or healthcare-associated.

Isolates of $S$. Typhi or S. Paratyphi A that were susceptible to chloramphenicol, ampicillin, trimethoprim/ sulfamethoxazole, ceftriaxone, ofloxacin and nalidixic acid were termed fully susceptible and those that were resistant to chloramphenicol, ampicillin and trimethoprim/sulfamethoxazole were considered MDR. Isolates of $S$. Typhi or S. Paratyphi A that were resistant to nalidixic acid were confirmed to have decreased fluoroquinolone susceptibility by ciprofloxacin E-test. A ciprofloxacin MIC of $0.1-1.0 \mu \mathrm{g} / \mathrm{mL}$ was defined as decreased ciprofloxacin susceptibility.

\subsection{Statistical analysis}

Time trends (over the 15-year period), including the proportion of cultured isolates by year, the antimicrobial susceptibility patterns and HIV positivity rate were determined by logistic regression, therefore, odds ratios, when presented are shown in per unit of time (per year). All statistical analysis was performed using Stata version 11 (StataCorp LP, College Station, TX, USA); a p-value of $\leq 0.05$ was considered significant.

\section{Results}

\subsection{General observations}

During the 15-year period from 1994-2008, 418534 patients were admitted to the HTD. Amongst these, 66111 had at least one blood culture performed for a suspected bloodstream infection, corresponding to 158 blood cultures performed per 1000 hospital admissions. The mean age of the patients who had a blood culture performed was 26 (range 1-103) years; 15205 (23.0\%) were children $<15$ years, and 37022 (56.0\%) were male. Over this period, there were 7645 clinically relevant (according to the criterion described in the methods) bloodstream infection episodes, equivalent to an overall positive blood culture rate of 116/1000 blood cultures and 18/1000 hospital admissions. The annual rate of positive cultures varied throughout the 15-year period, ranging from 12/1000 to $37 / 1000$ hospital admissions. Prior to the use of the BACTEC system in 1998, the proportion of positive cultures fluctuated, yet remained above $12 \%$ annually. The positive culture rate then declined from $16.2 \%$ (761/4694) in 1998 to $10.5 \%$ (360/3438) in 1999 and remained below 10\% thereafter, corresponding to a rate of $<17$ positive blood cultures per 1000 hospital admissions.

\subsection{HIV seropositive rate}

The annual proportions of patients admitted during the 15-year period that were HIV seropositive are shown in Figure 1. In 1994, 0.15\% (32/21 492) of patients who attended the HTD were HIV seropositive. The proportion of HIV in patients attending the HTD increased annually, approximately doubling every three years 

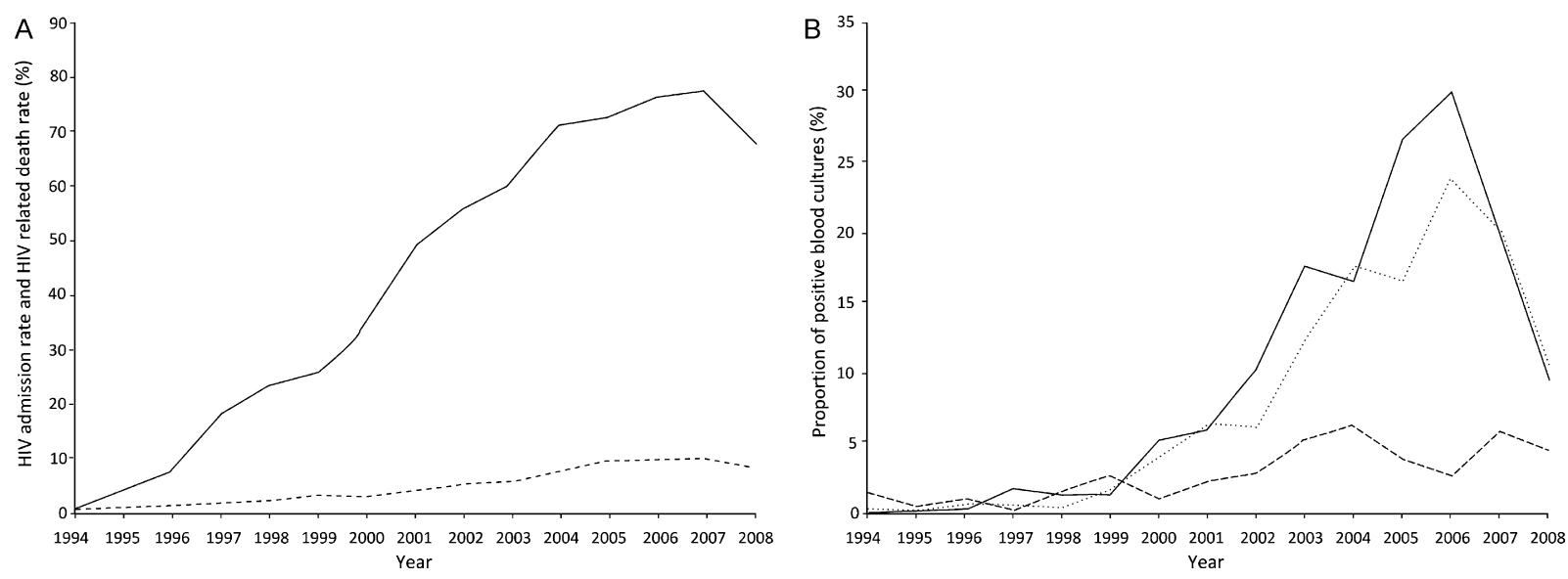

Figure 1. HIV prevalence and HIV related bloodstream infections.

A: Graph showing the annual proportions of patients admitted to the Hospital for Tropical Diseases with a seropositive HIV diagnosis (broken line) and the proportion of annual HIV related deaths (solid line).

B: Graph demonstrating the proportion of positive blood cultures from which Cryptococcus neoformans (solid line), Penicillium marneffei (dotted line) or Non-Typhoidal salmonellae (NTS) (broken line) was isolated.

(OR 1.2323, 95\% CI [1.2269, 1.2377], $\mathrm{p}<0.0001$ ). The proportion of HIV seropositive patients admitted to the hospital peaked at $9.1 \%(2946 / 32441)$ in 2007 , declining to $<7.7 \%$ (2629/34 221) of admissions by 2008 (Figure 1 ).

\subsection{Gram-negative bacterial infections}

The distribution of the pathogens isolated from blood and their corresponding logistic regressions are shown in Table 1. The most commonly isolated pathogen was S. Typhi, responsible for $41.6 \%$ (3178/7645) of all bloodstream infections over the 15-year period. Until 2002 $S$. Typhi was the predominant organism annually, and was the major cause of bloodstream infections during the fiveyear periods of 1994 to 1998 and 1999 to 2003 (Figure 2). Conversely, S. Paratyphi A was sporadic, accounting for only $1.2 \%$ (94/7646) of the total proportion of positive cultures. Yet, both $S$. Typhi and S. Paratyphi A demonstrated a significant proportional decline over the study period (Figure 2 and Figure 3). The decline of S. Typhi over the 15 years was calculated to correspond to a decrease of approximately $30 \%$ annually (OR $0.6993,95 \%$ CI [0.6885, 0.7103 ], $\mathrm{p}<0.0001$ ). Conversely, the proportion of NTS significantly increased over the same period (OR 1.1586, 95\% CI [1.12, 1.1985], p < 0.0001) (Figure 1 and Figure 2). This increase occurred mainly after 1998, corresponding with a HIV prevalence rate of $>2 \%$ of all hospital admissions (Figure 1). The ratios of NTS with respect to Klebsiella spp. (used here as a comparative benchmark) declined dramatically over the three defined five-year periods, being 1:3.3, $1: 3$ and $1: 1.1$, respectively.

Of the other Gram negative bacteria isolated, E. coli and Klebsiella spp. (principally K. pneumonia) were the most common (Table 1), with Pseudomonas aeruginosa, Neisseria meningitidis, Haemophilus influenzae, Burkholderia pseudomallei and Burkholderia cepacia being consistently yet infrequently isolated. The proportion of $E$. coli isolation was approximately twice that of Klebsiella spp. (as a comparative benchmark) throughout the successive five-year periods (Figure 2), demonstrating relative ratios of $0.45: 1$, $0.5: 1$ and $0.38: 1$, respectively. Both E. coli and Klebsiella spp. exhibited a small proportional increase over 15 years (OR 1.0724, 95\% CI [1.0557, 1.0893], p $<0.0001$ for E. coli and OR $1.043495 \%$ CI [1.0201, 1.0672], $\mathrm{p}<0.0001$ for Klebsiella spp.).

\subsection{Gram-positive bacterial infections}

The most commonly isolated Gram-positive organisms were Staphylococcus aureus and Streptococcus pneumoniae, comprising 5.4\% (412/7645) and 1.5\% (113/7645) of all positive blood cultures, respectively. The annual proportional rate of Staphylococcus aureus isolation over the 15-year period was variable, yet demonstrated a slight overall increase, potentially skewed by a peak in Staphylococcus aureus isolation between 1999 and 2001 (Table 1). Comparatively, the rate of Streptococcus pneumoniae isolations was also consistent, demonstrating a slight increase parallel to that of Staphylococcus aureus. Other Streptococci including S. suis, S. sanguis and S. milleri were also isolated, but with limited frequency.

\subsection{Fungal infections}

HIV was first diagnosed at the HTD in 1990 and Cryptococcus neoformans and Penicillium marneffei were first isolated from blood cultures in 1996 (Table 1 and Figure 1). In 2005 Cryptococcus neoformans or Penicillium marneffei were the two most commonly isolated bloodstream pathogens, representing $26.6 \%(113 / 425)$ and $16.5 \%$ (70/425) of all positive blood cultures, respectively. This dramatic increase correlated with an increase in HIV admissions, over the same time period (Figure 1). In comparison to the other isolated pathogens, these fungi demonstrated the largest proportional shift in bloodstream infection etiology over the 15-year period (OR 1.2955 95\% CI [1.2659, 1.3259], $\mathrm{p}<0.0001$ for Cryptococcus neoformans and OR 1.3254, 95\% CI [1.2906, 1.3612], $\mathrm{p}<0.0001$ for Penicillium marneffei). 
Table 1

Clinically relevant organisms isolated from blood at the Hospital for Tropical Diseases in Ho Chi Minh City (1994-2008)

\begin{tabular}{|c|c|c|c|c|c|c|c|c|c|c|c|c|c|c|c|c|c|c|}
\hline Pathogen $^{\mathrm{a}}$ & 1994 & 1995 & 1996 & 1997 & 1998 & 1999 & 2000 & 2001 & 2002 & 2003 & 2004 & 2005 & 2006 & 2007 & 2008 & $\mathrm{OR}^{\mathrm{b}}$ & - value ${ }^{b}$ & $95 \% \mathrm{CI}$ \\
\hline Salmon & $\begin{array}{l}497 \\
(73.63)\end{array}$ & $\begin{array}{l}716 \\
(78.59)\end{array}$ & $\begin{array}{l}357 \\
(73.61)\end{array}$ & $\begin{array}{l}346 \\
(69.34)\end{array}$ & $\begin{array}{l}599 \\
(78.71)\end{array}$ & $\begin{array}{l}171 \\
(47.50)\end{array}$ & $\begin{array}{l}96 \\
(30.00)\end{array}$ & $\begin{array}{l}80 \\
(25.08)\end{array}$ & $\begin{array}{l}91 \\
(22.86)\end{array}$ & $\begin{array}{l}49 \\
(13.69)\end{array}$ & $\begin{array}{l}52 \\
(11.30)\end{array}$ & $\begin{array}{l}30 \\
(7.06)\end{array}$ & $\begin{array}{l}20 \\
(4.08)\end{array}$ & $\begin{array}{l}40 \\
(6.28)\end{array}$ & $\begin{array}{l}34 \\
(6.22)\end{array}$ & 0.7 & 01 & $.69-0.71$ \\
\hline Salmonella Paratyphi A & $\begin{array}{l}10 \\
(1.48)\end{array}$ & $\begin{array}{l}24 \\
(2.63)\end{array}$ & $\begin{array}{l}10 \\
(2.06)\end{array}$ & $\begin{array}{l}15 \\
(3.01)\end{array}$ & $\begin{array}{l}6 \\
(0.79)\end{array}$ & $\begin{array}{l}5 \\
(1.39)\end{array}$ & $\begin{array}{l}6 \\
(1.88)\end{array}$ & $\begin{array}{l}1 \\
(0.31)\end{array}$ & $\begin{array}{l}4 \\
(1.01)\end{array}$ & $\begin{array}{l}1 \\
(0.28)\end{array}$ & $\begin{array}{l}6 \\
(1.30)\end{array}$ & $\begin{array}{l}3 \\
(0.71)\end{array}$ & $\begin{array}{l}0 \\
(0.00)\end{array}$ & $\begin{array}{l}3 \\
(0.47)\end{array}$ & $\begin{array}{l}0 \\
(0.00)\end{array}$ & 0.86 & 0.001 & $.82-0.91$ \\
\hline Escherichia coli & $\begin{array}{l}29 \\
(4.30)\end{array}$ & $\begin{array}{l}48 \\
(5.27)\end{array}$ & $\begin{array}{l}37 \\
(7.63)\end{array}$ & $\begin{array}{l}47 \\
(9.42)\end{array}$ & $\begin{array}{l}41 \\
(5.39)\end{array}$ & $\begin{array}{l}47 \\
(13.06)\end{array}$ & $\begin{array}{l}52 \\
(16.25)\end{array}$ & $\begin{array}{l}60 \\
(18.81)\end{array}$ & $\begin{array}{l}73 \\
(18.34)\end{array}$ & $\begin{array}{l}54 \\
(15.08)\end{array}$ & $\begin{array}{l}63 \\
(13.70)\end{array}$ & $\begin{array}{l}64 \\
(15.06)\end{array}$ & $\begin{array}{l}57 \\
(11.63)\end{array}$ & $\begin{array}{l}86 \\
(13.50)\end{array}$ & $\begin{array}{l}63 \\
(11.52)\end{array}$ & 7 & 1 & 1.09 \\
\hline Klebsiella spp. & $\begin{array}{l}26 \\
(3.85)\end{array}$ & $\begin{array}{l}15 \\
(1.65)\end{array}$ & $\begin{array}{l}15 \\
(3.09)\end{array}$ & $\begin{array}{l}16 \\
(3.21)\end{array}$ & $\begin{array}{l}19 \\
(2.50)\end{array}$ & $\begin{array}{l}31 \\
(8.61)\end{array}$ & $\begin{array}{l}27 \\
(8.44)\end{array}$ & $\begin{array}{l}32 \\
(10.03)\end{array}$ & $\begin{array}{l}32 \\
(8.04)\end{array}$ & $\begin{array}{l}22 \\
(6.15)\end{array}$ & $\begin{array}{l}23 \\
(5.00)\end{array}$ & $\begin{array}{l}19 \\
(4.47)\end{array}$ & $\begin{array}{l}30 \\
(6.12)\end{array}$ & $\begin{array}{l}33 \\
(5.18)\end{array}$ & $\begin{array}{l}20 \\
(3.66)\end{array}$ & 1.04 & $<0.001$ & $1.02-1.07$ \\
\hline & $\begin{array}{l}9 \\
(1.33)\end{array}$ & $\begin{array}{l}3 \\
(0.33)\end{array}$ & $\begin{array}{l}4 \\
(0.82)\end{array}$ & $\begin{array}{l}1 \\
(0.20)\end{array}$ & $\begin{array}{l}11 \\
(1.45)\end{array}$ & $\begin{array}{l}9 \\
(2.50)\end{array}$ & $\begin{array}{l}3 \\
(0.94)\end{array}$ & $\begin{array}{l}7 \\
(2.19)\end{array}$ & $\begin{array}{l}11 \\
(2.76)\end{array}$ & $\begin{array}{l}18 \\
(5.03)\end{array}$ & $\begin{array}{l}28 \\
(6.09)\end{array}$ & $\begin{array}{l}16 \\
(3.76)\end{array}$ & $\begin{array}{l}13 \\
(2.65)\end{array}$ & $\begin{array}{l}36 \\
(5.65)\end{array}$ & $\begin{array}{l}24 \\
(4.39)\end{array}$ & 6 & $<0.001$ & .20 \\
\hline Pseudomonas aeruginosa & $\begin{array}{l}1 \\
(0.15)\end{array}$ & $\begin{array}{l}3 \\
(0.33)\end{array}$ & $\begin{array}{l}7 \\
(1.44)\end{array}$ & $\begin{array}{l}2 \\
(0.40)\end{array}$ & $\begin{array}{l}3 \\
(0.39)\end{array}$ & $\begin{array}{l}5 \\
(1.39)\end{array}$ & $\begin{array}{l}4 \\
(1.25)\end{array}$ & $\begin{array}{l}3 \\
(0.94)\end{array}$ & $\begin{array}{l}4 \\
(1.01)\end{array}$ & $\begin{array}{l}4 \\
(1.12)\end{array}$ & $\begin{array}{l}11 \\
(2.39)\end{array}$ & $\begin{array}{l}11 \\
(2.59)\end{array}$ & $\begin{array}{l}10 \\
(2.04)\end{array}$ & $\begin{array}{l}16 \\
(2.51)\end{array}$ & $\begin{array}{l}10 \\
(1.83)\end{array}$ & 1.14 & $<0.001$ & $1.09-1.2$ \\
\hline Neis & $\begin{array}{l}4 \\
(0.59)\end{array}$ & $\begin{array}{l}4 \\
(0.44)\end{array}$ & $\begin{array}{l}0 \\
(0.00)\end{array}$ & $\begin{array}{l}4 \\
(0.80)\end{array}$ & $\begin{array}{l}2 \\
(0.26)\end{array}$ & $\begin{array}{l}4 \\
(1.11)\end{array}$ & $\begin{array}{l}1 \\
(0.31)\end{array}$ & $\begin{array}{l}0 \\
(0.00)\end{array}$ & $\begin{array}{l}3 \\
(0.75)\end{array}$ & $\begin{array}{l}1 \\
(0.28)\end{array}$ & $\begin{array}{l}3 \\
(0.65)\end{array}$ & $\begin{array}{l}3 \\
(0.71)\end{array}$ & $\begin{array}{l}3 \\
(0.61)\end{array}$ & $\begin{array}{l}1 \\
(0.16)\end{array}$ & $\begin{array}{l}0 \\
(0.00)\end{array}$ & .97 & 0.447 & .05 \\
\hline Haemophilus influenzae & $\begin{array}{l}1 \\
(0.15)\end{array}$ & $\begin{array}{l}1 \\
(0.11)\end{array}$ & $\begin{array}{l}1 \\
(0.21)\end{array}$ & $\begin{array}{l}0 \\
(0.00)\end{array}$ & $\begin{array}{l}1 \\
(0.13)\end{array}$ & $\begin{array}{l}4 \\
(1.11)\end{array}$ & $\begin{array}{l}1 \\
(0.31)\end{array}$ & $\begin{array}{l}1 \\
(0.31)\end{array}$ & $\begin{array}{l}0 \\
(0.00)\end{array}$ & $\begin{array}{l}0 \\
(0.00)\end{array}$ & $\begin{array}{l}3 \\
(0.65)\end{array}$ & $\begin{array}{l}1 \\
(0.24)\end{array}$ & $\begin{array}{l}3 \\
(0.61)\end{array}$ & $\begin{array}{l}2 \\
(0.31)\end{array}$ & $\begin{array}{l}2 \\
(0.37)\end{array}$ & 1.08 & 0.119 & $0.98-1.18$ \\
\hline Stap & $\begin{array}{l}24 \\
(3 .\end{array}$ & $\begin{array}{l}24 \\
(2.63)\end{array}$ & $\begin{array}{l}19 \\
(3.92)\end{array}$ & $\begin{array}{l}19 \\
(3.81)\end{array}$ & $\begin{array}{l}19 \\
(2.50)\end{array}$ & $\begin{array}{l}24 \\
(6.67)\end{array}$ & $\begin{array}{l}32 \\
(10.00)\end{array}$ & $\begin{array}{l}39 \\
(12.23)\end{array}$ & $\begin{array}{l}31 \\
(7.79)\end{array}$ & $\begin{array}{l}20 \\
(5.59)\end{array}$ & $\begin{array}{l}34 \\
(7.39)\end{array}$ & $\begin{array}{l}25 \\
(5.88)\end{array}$ & $\begin{array}{l}36 \\
(7.35)\end{array}$ & $\begin{array}{l}35 \\
(5.49)\end{array}$ & $\begin{array}{l}31 \\
(5.67)\end{array}$ & 1.01 & 0.301 & .03 \\
\hline Streptococcus pneumoniae & $\begin{array}{l}5 \\
(0.74)\end{array}$ & $\begin{array}{l}2 \\
(0.22)\end{array}$ & $\begin{array}{l}2 \\
(0.41)\end{array}$ & $\begin{array}{l}3 \\
(0.60)\end{array}$ & $\begin{array}{l}9 \\
(1.18)\end{array}$ & $\begin{array}{l}7 \\
(1.94)\end{array}$ & $\begin{array}{l}6 \\
(1.88)\end{array}$ & $\begin{array}{l}3 \\
(0.94)\end{array}$ & $\begin{array}{l}10 \\
(2.51)\end{array}$ & $\begin{array}{l}12 \\
(3.35)\end{array}$ & $\begin{array}{l}14 \\
(3.04)\end{array}$ & $\begin{array}{l}7 \\
(1.65)\end{array}$ & $\begin{array}{l}9 \\
(1.84)\end{array}$ & $\begin{array}{l}11 \\
(1.73)\end{array}$ & $\begin{array}{l}13 \\
(2.38)\end{array}$ & 1.11 & $<0.001$ & $.06-1.15$ \\
\hline Oth & $\begin{array}{l}21 \\
(3.11)\end{array}$ & $\begin{array}{l}32 \\
(3.51)\end{array}$ & $\begin{array}{l}16 \\
(3.30)\end{array}$ & $\begin{array}{l}22 \\
(4.41)\end{array}$ & $\begin{array}{l}30 \\
(3.94)\end{array}$ & $\begin{array}{l}28 \\
(7.78)\end{array}$ & $\begin{array}{l}38 \\
(11.88)\end{array}$ & $\begin{array}{l}40 \\
(12.54)\end{array}$ & $\begin{array}{l}49 \\
(12.31)\end{array}$ & $\begin{array}{l}12 \\
(3.35)\end{array}$ & $\begin{array}{l}15 \\
(3.26)\end{array}$ & $\begin{array}{l}7 \\
(1.65)\end{array}$ & $\begin{array}{l}13 \\
(2.65)\end{array}$ & $\begin{array}{l}15 \\
(2.35)\end{array}$ & $\begin{array}{l}19 \\
(3.47)\end{array}$ & 0.99 & 0.303 & 1.01 \\
\hline Cryptococcus neoformans & $\begin{array}{l}0 \\
(0.00)\end{array}$ & $\begin{array}{l}0 \\
(0.00)\end{array}$ & $\begin{array}{l}1 \\
(0.21)\end{array}$ & $\begin{array}{l}8 \\
(1.60)\end{array}$ & $\begin{array}{l}9 \\
(1.18)\end{array}$ & $\begin{array}{l}5 \\
(1.39)\end{array}$ & $\begin{array}{l}16 \\
(5.00)\end{array}$ & $\begin{array}{l}19 \\
(5.96)\end{array}$ & $\begin{array}{l}41 \\
(10.30)\end{array}$ & $\begin{array}{l}63 \\
(17.60)\end{array}$ & $\begin{array}{l}76 \\
(16.52)\end{array}$ & $\begin{array}{l}113 \\
(26.59)\end{array}$ & $\begin{array}{l}147 \\
(30.00)\end{array}$ & $\begin{array}{l}121 \\
(19.00)\end{array}$ & $\begin{array}{l}52 \\
(9.51)\end{array}$ & 1.3 & $<0.001$ & $1.27-1.33$ \\
\hline Penicillium marneffei & $\begin{array}{l}1 \\
(0.00)\end{array}$ & $\begin{array}{l}0 \\
(0.00)\end{array}$ & $\begin{array}{l}2 \\
(0.410\end{array}$ & $\begin{array}{l}2 \\
(0.40)\end{array}$ & $\begin{array}{l}2 \\
(0.26)\end{array}$ & $\begin{array}{l}6 \\
(1.67)\end{array}$ & $\begin{array}{l}13 \\
(4.06)\end{array}$ & $\begin{array}{l}20 \\
(6.27)\end{array}$ & $\begin{array}{l}24 \\
(6.03)\end{array}$ & $\begin{array}{l}44 \\
12.29)\end{array}$ & $\begin{array}{l}81 \\
(17.61)\end{array}$ & $\begin{array}{l}70 \\
(16.47)\end{array}$ & $\begin{array}{l}117 \\
(23.88)\end{array}$ & $\begin{array}{l}128 \\
(20.09)\end{array}$ & $\begin{array}{l}57 \\
(10.42)\end{array}$ & 1.32 & $<0.001$ & $1.29-1.36$ \\
\hline Candida spp. & $\begin{array}{l}2 \\
(0.00)\end{array}$ & $\begin{array}{l}0 \\
(0.00)\end{array}$ & $\begin{array}{l}0 \\
(0.00)\end{array}$ & $\begin{array}{l}0 \\
(0.00)\end{array}$ & $\begin{array}{l}1 \\
(0.13)\end{array}$ & $\begin{array}{l}4 \\
(1.11)\end{array}$ & $\begin{array}{l}4 \\
(1.25)\end{array}$ & $\begin{array}{l}0 \\
(0.00)\end{array}$ & $\begin{array}{l}2 \\
(0.50)\end{array}$ & $\begin{array}{l}1 \\
(0.28)\end{array}$ & $\begin{array}{l}2 \\
(0.43)\end{array}$ & $\begin{array}{l}1 \\
(0.24)\end{array}$ & $\begin{array}{l}2 \\
(0.41)\end{array}$ & $\begin{array}{l}2 \\
(0.31)\end{array}$ & $\begin{array}{l}4 \\
(0.73)\end{array}$ & 1.09 & 0.050 & $1-1.19$ \\
\hline Total $^{c}$ & 675 & 911 & 485 & 499 & 761 & 360 & 320 & 319 & 675 & 911 & 485 & 499 & 761 & 360 & 320 & & & \\
\hline
\end{tabular}

a Data presented as actual counts and percentages (\%).

${ }^{\mathrm{b}} \mathrm{p}$-value and OR calculated by logistic regression.

${ }^{\mathrm{c}}$ Total number of positive blood cultures for that year (including additional organisms not presented in the table). 
1994 - 1998
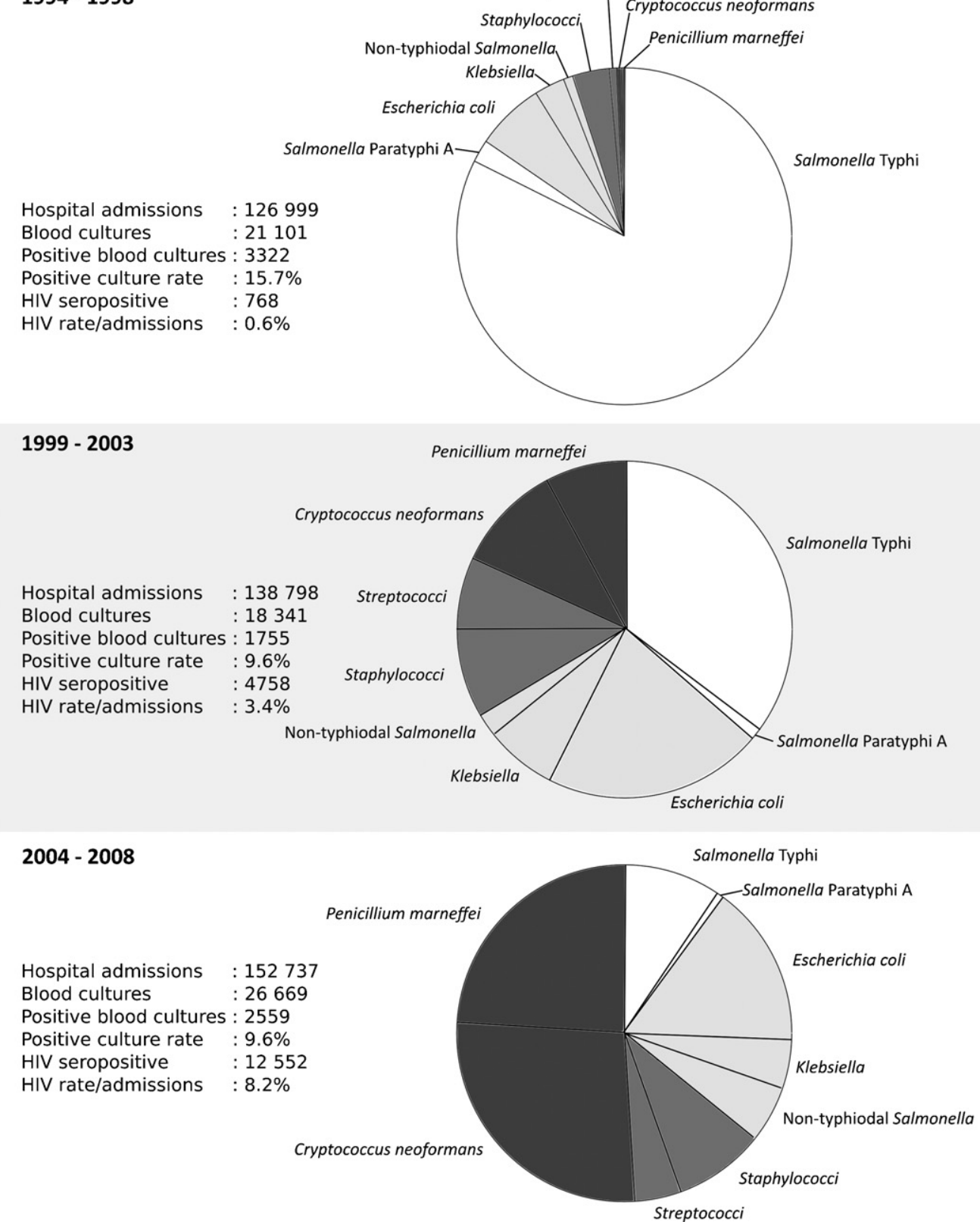

Figure 2. The distribution of bloodstream pathogens over three successive five-year periods.

Pie charts showing combined data from 1994-1998, 1999-2003 and 2004-2008. Proportions correspond to the organisms represented in the chart only (total data is shown in Table 1) and are shaded by typhoidal Salmonella (white), other Gram-negative organisms (light grey), Gram-positive organisms (medium grey) and fungi (dark grey).

\subsection{Antimicrobial susceptibility patterns}

The decreasing proportion of $S$. Typhi isolated from blood cultures and the corresponding nalidixic acid susceptibility and MDR patterns are shown in Figure 3, which also highlights the years of $1995(\mathrm{n}=716)$ and 1998 $(n=599)$ as those with the highest number of $S$. Typhi positive blood cultures. There was a clinically important shift within the $S$. Typhi isolated over the 15 year period, as MDR strains represented 92.0\% (659/716) of all $S$. Typhi isolates in $1995,87.9 \%$ (527/599) in 1998 , but only $17.6 \%(6 / 34)$ in 2008 , dropping by approximately $18 \%$ $(\mathrm{p}<0.001)$ per year. Multidrug resistant $S$. Typhi strains were gradually replaced by nalidixic acid resistant $S$. Typhi strains (Figure 3). As such, nalidixic acid resistant strains represented $1.9 \%$ (14/716) of all $S$. Typhi isolates in 1995, $44.0 \%(264 / 599)$ in 1998 and 50.0\% (17/34) in 2008.

We identified a gradual decline in the proportion of E. coli isolates susceptible to gentamicin, ofloxacin and ceftriaxone (Figure 4). For E. coli this was most evident with 


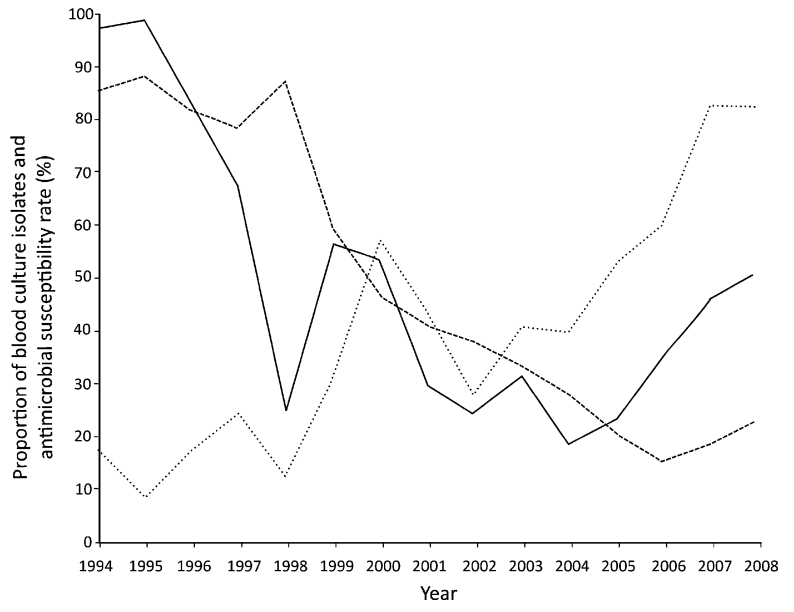

Figure 3. The prevalence and changing antimicrobial susceptibility pattern of Salmonella Typhi.

Graph showing the proportion of $S$. Typhi isolated from blood cultures between 1994 and 2008 (broken line). The proportion of S. Typhi strains that were susceptible to nalidixic acid is shown by the solid line and the proportion of non multidrug resistant $S$. Typhi strains is shown by the dotted line.

ceftriaxone (OR 0.7825 95\% CI [0.8238, 0.8766], p < 0.0001). Klebsiella spp. also exhibited a significant decrease in susceptibility to gentamicin, ofloxacin and ceftriaxone, although the decline was less pronounced than that of E. coli (Figure 4). The sharp decline in the proportion of $K$. pneumonia strains susceptible to gentamicin, ofloxacin and ceftriaxone in 1999 was linked to a hospital outbreak of this organism. Within the Gram-positive organisms, the proportion of methicillin resistant Staphylococcus aureus isolates varied between $0 \%(0 / 18$ in 1995) and $17 \%$ (3/18 in 2003) with no significant trend during the 15 -year period. The proportion of penicillin resistant Streptococcus pneumoniae increased from 3/20 (15\%) during 1994-1997 to $10 / 25$ (40\%) during $1998-2001$, and $36 / 76$ (47\%) in

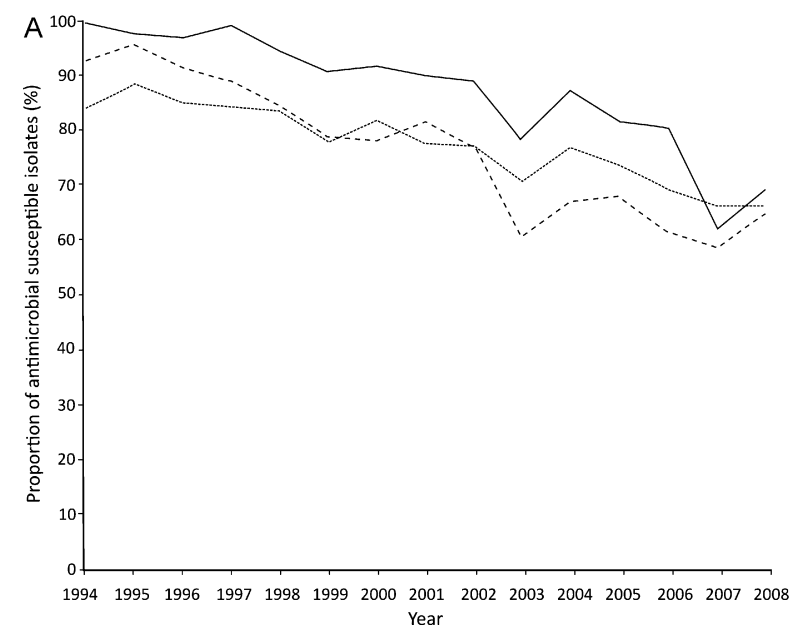

2002-2008, yet this pattern was also not statistically significant.

\section{Discussion}

The spectrum of organisms causing bloodstream infection in developing countries and developed countries is highly variable and highly dependent on location. Bloodstream infections in industrialized countries are largely hospital associated, often caused by coagulase-negative Staphylococcus spp., Staphylococcus aureus, Enterococcus spp., E. coli, Klebsiella spp. and Candida. ${ }^{22}$ Nosocomial infections make a smaller contribution in developing countries, and enteric pathogens, such as Salmonella, which are generally community transmitted, are habitually the dominant etiological agents. ${ }^{5}$

This study documents an important shift in the burden of bloodstream infections, identifying a decline of typhoid fever and a concurrent rise of HIV-associated opportunistic pathogens. However, there are some limitations, mainly related to the fact that our study focuses on a single health care center. The HTD serves both the local community and is the largest secondary and tertiary infectious disease referral center in the south of Vietnam. The data reported here reflects the general pattern of referral of patients to HTD and, therefore, may not be representative of the situation in other hospitals in the city. As such, the low number of positive blood cultures with Streptococcus pneumoniae, $H$. influenzae and $N$. meningitidis highlights the fact that most children with meningitis or pneumonia are referred to one of two pediatric hospitals within the city. A previous study from one of these pediatric hospitals demonstrated that Streptococcus pneumoniae was the commonest cause of bacteremic pneumonia in infants and children, and was second to $H$. influenzae $\mathrm{B}$ as the leading cause of meningitis. ${ }^{23}$ We were also unable to differentiate community from healthcare associated infections and to ascertain whether an isolated pathogen caused a true

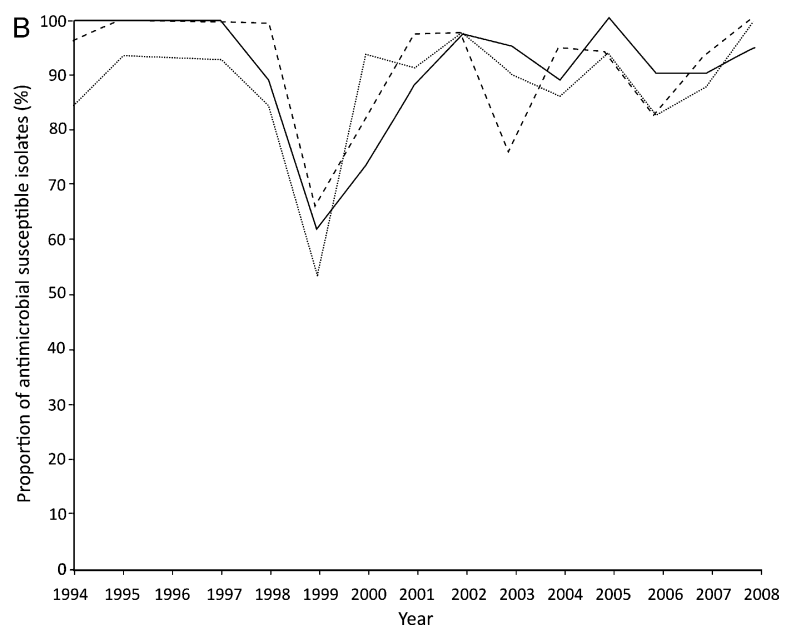

Figure 4. Antimicrobial susceptibility patterns of Escherichia coli and Klebsiella spp.

A: Graph showing the proportion of E. coli strains isolated from blood exhibiting susceptibility to gentamicin (solid line), ofloxacin (broken line) and ceftriaxone (dotted line); number tested, 819.

B: Graph showing the proportion of Klebsiella spp. strains isolated from blood exhibiting susceptibility to the same three antimicrobials, shading as with $E$. coli; number tested, 338. 
bloodstream infection in an individual patient, since it was not feasible to obtain charts for all patients with positive cultures. Furthermore, blood cultures for Mycobacterium tuberculosis were not routinely performed and so we are unable to assess the overall contribution of this highly relevant organism. Yet, we recognize tuberculosis as an important public health problem in Vietnam, which has been exacerbated by the HIV epidemic. Corresponding with this, in a previous case specific cross-sectional study in this same center, $M$. tuberculosis was the commonest isolate from blood in febrile HIV seropositive adults. ${ }^{14}$

Our study illustrates how the availability of a blood culture system allows identification of a range of pathogens causing bloodstream infections and an association of the changing pattern of antimicrobial susceptibility over a longitudinal period. Using the blood culture methods defined here, clinically relevant positive cultures occurred in $18 / 1000$ hospital admissions (range 10.5-35.4/1,000). This rate is greater than in a study conducted in Laos (9; range $7-11 / 1000)^{17}$ and comparable to the blood culture study conducted by Rodriguez-Creixems and coworkers in Spain (9; range 16-31.2/1000 admissions). ${ }^{24}$ Yet, we consider it is likely to be an underestimate of the true rate of bloodstream infections, as prior antimicrobial therapy in the community is highly prevalent among the patients attending HTD.

An increase in NTS infections was apparent, and was coupled with an increase in Cryptococcus neoformans and Penicillium marneffei infections. We have previously demonstrated the close temporal relationship between Penicillium marneffei and HIV/AIDS admissions at HTD. ${ }^{25}$ Here we show a corresponding temporal association with HIV/AIDS and NTS, a relationship that has been shown in Africa and in other parts of Asia, such as Taiwan and Thailand. ${ }^{26,27}$ Yet, our data do not allow assessment of specific clinical features of NTS infections or the overall case fatality rate. Additionally, data was not available on the individual serovars causing infection. Thus, we cannot confirm the presence or any epidemiological significant of S. Typhimurium sequence type 313 , which has been associated with invasive NTS disease with a high mortality rate in sub-Saharan Africa. ${ }^{28}$

Antimicrobial susceptibility within $S$. Typhi changed substantially over the study period; in 1990, less than $1 \%$ of $S$. Typhi and $S$. Paratyphi A isolates at the HTD were MDR, and none were nalidixic acid resistant. The peaks of S. Typhi isolations in 1995 and in 1998 coincided with the identification of $90 \%$ of S. Typhi isolates being MDR, ${ }^{29}$ and resistant to nalidixic acid, respectively. ${ }^{30,31}$ Both years reflect protracted outbreaks of antimicrobial resistant typhoid fever over a wide geographical area. Following the outbreak of nalidixic acid resistant $S$. Typhi in 1998, vigorous efforts were made to improve sanitation in the affected districts of HCMC. This was probably the main contributor to the decline in the number of typhoid cases at HTD, as there has been no programme of typhoid vaccination in the HCMC area to explain this decline. Despite the trend in typhoid cases in HCMC, in the Mekong Delta provinces MDR and nalidixic acid resistant $S$. Typhi strains remain common and may be related to sanitation. ${ }^{32}$ However, unlike some areas of the Indian sub-continent, fully fluoroquinolone or ceftriaxone resistant isolates have not arisen in Vietnam. ${ }^{30,31}$ Unless typhoid has a seemingly unlikely resurgence in HCMC, the emergence and maintenance of fully fluoroquinolone or ceftriaxone resistant isolates seems equally unlikely. The antimicrobial susceptibilities of other organisms also demonstrated a shift. There was a gradual decline in the susceptibility of $E$. coli to gentamicin, ofloxacin and ceftriaxone and Streptococcus pneumoniae to penicillin. Other than those observed within Streptococcus pneumoniae the antimicrobial resistance levels are not yet low enough to compromise the use of these antimicrobials for treating sepsis in this location.

In this 15-year bloodstream infection study at the largest hospital for tropical infections in Vietnam, S. Typhi was the dominant bloodstream pathogen from 1994 to 2002, after which it declined dramatically. Since 2002, NTS and other opportunistic HIV-associated pathogens including Cryptococcus neoformans and Penicillium marneffei have replaced $S$. Typhi as the leading agents of bloodstream infections. This shift is likely to reflect a changing landscape of infectious disease related to the HIV epidemic, urbanization and secondary social determinants within Vietnam. According to government figures the national seroprevalence of HIV increased from $0.1 \%$ to $0.5 \%$ (\% adults between 15-49 years) from 1994 to $2008,{ }^{33}$ concurrently increasing with the proportion of the population living in cities, from $21.8 \%$ to $27.8 \%$, over the same time period (http://www.indexmundi.com/facts/vietnam). Furthermore, projects to improve sanitary conditions, with $94 \%$ of the 2008 urban population having adequate access to excreta disposal facilities, compared to only $70 \%$ in 1995 , have reduced the overall risk of water-borne infections (http://www.indexmundi.com/facts/vietnam). Therefore, we conclude that, as with many countries in Asia, Vietnam has undergone a rapid economic transition, and HIV-associated opportunistic pathogens have now emerged as the leading source of bloodstream infections and the primary cause of mortality in hospitalized patients in this location.

Authors' contributions: The concept and the design of the study were performed by CMP, CD, JJF, NVVC and SB. The analysis and interpretation of data was performed by TVTN, CMP, TL, NPHL, TSD, JIC, NVMH, LTD, JW, TTH, JND and SB. This manuscript was drafted by TVTN, CMP, TL and SB and critically revised for intellectual content by NPHL, TSD, JIC, NVMH, LTD, JW, CD, TTH, JND, JJF and NVVC. All authors confirmed the final approval of the version of the manuscript to be published. Guarantor of the article: SB.

Acknowledgements: We thank the hospital leaders and the microbiology staff at the Hospital for Tropical Diseases for their assistance with this study.

Funding: This work was supported by The Wellcome Trust of Great Britain, Euston Road, London, United Kingdom. TL is supported by the Fogarty International Clinical Research Fellowship through the US National Institute of Health. SB is supported by an OAK Foundation Fellowship through Oxford University (Grant number OAKF9). 
Conflicts of interest: None declared.

Ethical approval: Not required.

\section{References}

1. Chierakul W, Rajanuwong A, Wuthiekanun V, Teerawattanasook N, Gasiprong M, Simpson A, et al. The changing pattern of bloodstream infections associated with the rise in HIV prevalence in northeastern Thailand. Trans $R$ Soc Trop Med Hyg 2004;98: 678-86.

2. Biedenbach DJ, Moet GJ, Jones RN. Occurrence and antimicrobial resistance pattern comparisons among bloodstream infection isolates from the SENTRY Antimicrobial Surveillance Program (1997-2002). Diagn Microbiol Infect Dis 2004;50:59-69.

3. Chau TT, Campbell JI, Galindo CM, Van Minh Hoang N, Diep TS, Nga TT, et al. Antimicrobial drug resistance of Salmonella enterica serovar typhi in Asia and molecular mechanism of reduced susceptibility to the fluoroquinolones. Antimicrob Agents Chemother 2007;51:4315-23.

4. Hoa NT, Diep TS, Wain J, Parry CM, Hien TT, Smith MD, et al. Community-acquired septicaemia in southern Viet Nam: the importance of multidrug-resistant Salmonella typhi. Trans $R$ Soc Trop Med Hyg 1998;92:503-8.

5. Maskey AP, Basnyat B, Thwaites GE, Campbell JI, Farrar JJ, Zimmerman MD. Emerging trends in enteric fever in Nepal: 9124 cases confirmed by blood culture 1993-2003. Trans $R$ Soc Trop Med Hyg 2008;102:91-5.

6. Ochiai RL, Wang X, von Seidlein L, Yang J, Bhutta ZA, Bhattacharya SK, et al. Salmonella paratyphi A rates, Asia. Emerg Infect Dis 2005;11:1764-6.

7. Gordon MA, Walsh AL, Chaponda M, Soko D, Mbvwinji M, Molyneux ME, et al. Bacteraemia and mortality among adult medical admissions in Malawi-predominance of non-typhi salmonellae and Streptococcus pneumoniae. J Infect 2001;42:44-9.

8. Mtove G, Amos B, von Seidlein L, Hendriksen I, Mwambuli A, Kimera J, et al. Invasive salmonellosis among children admitted to a rural Tanzanian hospital and a comparison with previous studies. PLoS One 2010;5:e9244.

9. Crump JA, Ramadhani HO, Morrissey AB, Saganda W, Mwako MS, Yang LY, et al. Invasive bacterial and fungal infections among hospitalized HIV-infected and HIV-uninfected adults and adolescents in northern Tanzania. Clin Infect Dis 2011;52:341-8.

10. Morpeth SC, Ramadhani HO, Crump JA. Invasive non-Typhi Salmonella disease in Africa. Clin Infect Dis 2009;49:606-11.

11. Gordon MA, Graham SM, Walsh AL, Wilson L, Phiri A, Molyneux E, et al. Epidemics of invasive Salmonella enterica serovar enteritidis and S. enterica Serovar typhimurium infection associated with multidrug resistance among adults and children in Malawi. Clin Infect Dis 2008;46:963-9.

12. Gordon MA, Kankwatira AM, Mwafulirwa G, Walsh AL, Hopkins MJ, Parry CM, et al. Invasive non-typhoid salmonellae establish systemic intracellular infection in HIV-infected adults: an emerging disease pathogenesis. Clin Infect Dis 2010;50:953-62.

13. Archibald LK, Pallangyo K, Kazembe P, Reller LB. Blood culture contamination in Tanzania, Malawi, and the United States: a microbiological tale of three cities. J Clin Microbiol 2006;44: 4425-9.

14. Louie JK, Chi NH, Thao le TT, Quang VM, Campbell J, Chau NV, et al. Opportunistic infections in hospitalized HIV-infected adults in Ho Chi Minh City, Vietnam: a cross-sectional study. Int J STD AIDS 2004;15:758-61.

15. Croucher NJ, Harris SR, Fraser C, Quail MA, Burton J, van der Linden $\mathrm{M}$, et al. Rapid pneumococcal evolution in response to clinical interventions. Science 2011;331:430-4.

16. Vinh H, Nhu NT, Nga TV, Duy PT, Campbell JI, Hoang NV, et al. A changing picture of shigellosis in southern Vietnam: shifting species dominance, antimicrobial susceptibility and clinical presentation. BMC Infect Dis 2009;9:204.

17. Phetsouvanh R, Phongmany S, Soukaloun D, Rasachak B, Soukhaseum $\mathrm{V}$, Soukhaseum S, et al. Causes of community-acquired bacteremia and patterns of antimicrobial resistance in Vientiane, Laos. Am J Trop Med Hyg 2006;75:978-85.

18. Sligl W, Taylor G, Brindley PG. Five years of nosocomial Gramnegative bacteremia in a general intensive care unit: epidemiology, antimicrobial susceptibility patterns, and outcomes. Int J Infect Dis 2006;10:320-5.

19. Clinical Laboratory and Standards Institute. Performance standards for antimicrobial susceptibility testing. Twentieth informational supplement ed. CLSI document M100-S20. 2010; http://www.clsi.org/source/orders/free/m100-s20.pdf [accessed 3 October 2011].

20. WHO)/UNAIDS. Guidance on provider-initiated HIV testing and counselling in health facilities. Geneva: World Health Organization/Joint United Nations Programme on HIV/AIDS. 2007; http://www.who.int/hiv/pub/vct/pitc2007/en/accessed [accessed 3 October 2011].

21. Socialist Republic of Vietnam. Decision of the Prime Minster approving the National Strategy on HIV/AIDS prevention and control in Viet Nam until 2010 with a vision to 2020 Hanoi: The Government, Socialist Republic of Vietnam; 2004 http://www.unaids.org.vn/local/gov/36-2004-qd-ttg.pdf [accessed 3 October 2011].

22. Wisplinghoff $\mathrm{H}$, Bischoff $\mathrm{T}$, Tallent SM, Seifert $\mathrm{H}$, Wenzel RP, Edmond MB. Nosocomial bloodstream infections in US hospitals: analysis of 24,179 cases from a prospective nationwide surveillance study. Clin Infect Dis 2004;39:309-17.

23. Tran TT, Le QT, Tran TN, Nguyen NT, Pedersen FK, Schlumberger M. The etiology of bacterial pneumonia and meningitis in Vietnam. Pediatr Infect Dis J 1998;17(Suppl):S192-4.

24. Rodriguez-Creixems M, Alcala L, Munoz P, Cercenado E, Vicente T, Bouza E. Bloodstream infections: evolution and trends in the microbiology workload, incidence, and etiology, 1985-2006. Medicine (Baltimore) 2008;87:234-49.

25. Le T, Huu Chi N, Kim Cuc NT, Manh Sieu TP, Shikuma CM, Farrar J, et al. AIDS-associated Penicillium marneffei infection of the centra nervous system. Clin Infect Dis 2011;51:1458-62.

26. Hung CC, Hung MN, Hsueh PR, Chang SY, Chen MY, Hsieh SM, et al. Risk of recurrent nontyphoid Salmonella bacteremia in HIV-infected patients in the era of highly active antiretroviral therapy and an increasing trend of fluoroquinolone resistance. Clin Infect Dis 2007:45: e60-7.

27. Kiratisin P. Bacteraemia due to non-typhoidal Salmonella in Thailand: clinical and microbiological analysis. Trans $R$ Soc Trop Med Hyg 2008;102:384-8.

28. Kingsley RA, Msefula CL, Thomson NR, Kariuki S, Holt KE, Gordon MA, et al. Epidemic multiple drug resistant Salmonella Typhimurium causing invasive disease in sub-Saharan Africa have a distinct genotype. Genome Res 2009;19:2279-87.

29. Parry CM. The treatment of multidrug-resistant and nalidixic acidresistant typhoid fever in Viet Nam. Trans $R$ Soc Trop Med Hyg 2004;98:413-22.

30. Gaind R, Paglietti B, Murgia M, Dawar R, Uzzau S, Cappuccinelli P, et al. Molecular characterization of ciprofloxacin-resistant Salmonella enterica serovar Typhi and Paratyphi A causing enteric fever in India. J Antimicrob Chemother 2006;58:1139-44.

31. Gokul BN, Menezes GA, Harish BN. ACC-1 beta-Lactamaseproducing Salmonella enterica Serovar Typhi, India. Emerg Infect Dis 2010;16:1170-1.

32. Holt KE, Dolecek C, Chau TT, Duy PT, La TT, Hoang NV, et al. Temporal fluctuation of multidrug resistant salmonella typhi haplotypes in the Mekong River delta region of Vietnam. PLoS Negl Trop Dis 2011:5:e929.

33. Ministry of Health Vietnam. Vietnam HIV/AIDS estimates and projections 2007-2012. Hanoi: Vietnam Administration for AIDS Control (VAAC); 2009. 